\title{
RANCANG BANGUN SISTEM INFORMASI PEMESANAN MENU MAKANAN BERBASIS WEB (STUDI KASUS: RESTORAN BUKIT RANDU BANDARA)
}

\author{
Tuti Handayani $^{1}$, Ipung Gunawan ${ }^{2}$, Rohmat Taufiq ${ }^{3}$ \\ 1,2,3 Teknik Informatika, Universitas Muhammadiyah Tangerang
}

\section{Article Info:}

Dikirim: 06 Juni 2020

Direvisi: 25 Juni 2020

Diterima: 30 Juni 2020

Tersedia Online: 30 Juni 2020

Penulis Korespondensi:

Tuti Handayani

Teknik Informatika, Universitas

Muhammadiyah Tangerang,

Indonesia

Email: tuti.hani80@gmail.com

\begin{abstract}
Abstrak: Restoran Bukit Randu Bandara melayani makanan dari seluruh customer yang berada di Tangerang dan merambah ke lokasi yang sangat jauh. Jumlah customer yang kian hari semakin bertambah. Beberapa masalah muncul terjadi, seperti banyaknya antrian customer ketika memesan makanan hingga timbul rasa kecewa para customer dan kesibukan para pelayan karena banyaknya customer. Restoran Bukit Randu tidak memiliki sistem pemesanan menu makanan secara online, sehingga kurang dapat bertahan dalam persaingan dengan restoran lainnya.. Hal inilah yang mendorong pemilik restoran agar memberikan pelayanan yang terbaik untuk customer dan tidak harus antri ketika memesan makanan. Penelitian ini membuat rancang bangun sistem informasi pemesanan menu makanan berbasis web. Dalam penelitian ini metode yang digunakan dengan cara observasi,yaitu mengamati alur proses sistem pemesanan, wawancara meliputi proses penilaian kualitas pelayanan yang sedang berjalan, studi kepustakaan. Metode perancangan sistemnya menggunakan Unified Modelling Language (UML) dan perancangan sistem menggunakan metode waterfall. Untuk pengujian sistemnya menggunakan Black Box Testing, yaitu proses login, pengelolaan data master dan pelaporan pada masing-masing user. Penelitian ini diharapkan dapat memperluas area pemasaran sehingga dapat menambah jumlah customer. Penelitian ini diharapkan website dapat membantu memberikan informasi ke customer sehingga customer mendapatkan informasi yang update dan menjadi solusi bagi customer yang ingin membeli makanan.
\end{abstract}

Kata kunci: rancang bangun; sistem informasi; pemesanan; waterfall; web.

\begin{abstract}
The Bukit Randu Bandara restaurant serves food from all customers in Tangerang and has traveled to very far locations. The number of customers is increasingly growing. Some problems arise, such as the number of customers queuing when ordering food to arise disappointed customers and the busyness of the waiters because of the large number of customers. Bukit Randu Restaurant does not have an online food ordering system, so it is less able to survive in competition with other restaurants. This is what encourages restaurant owners to provide the best service for customers and do not have to queue when ordering food. This research created a web-based food menu ordering information system design. In this research, the method used is by observation, which is observing the flow of the ordering system process, interviews include the process of evaluating the quality of services that are running, literature study. The system design method uses Unified Modeling Language (UML) and the system design uses the waterfall method. To test the system using Black Box Testing, namely the login process, master data management and reporting to each user. This research is expected to expand the marketing area so that it can increase the number of customers. This research is expected that the website can help provide information to customers so that customers get updated information and become a solution for customers who want to buy food.
\end{abstract}

Keywords: design and development; information systems; ordering; waterfall; web. 


\section{PENDAHULUAN}

Restoran Bukit Randu Bandara melayani makanan dari seluruh customer yang berada di Tangerang dan merambah ke lokasi yang sangat jauh. Jumlah customer yang kian hari semakin bertambah. Beberapa masalah muncul terjadi, seperti banyaknya antrian customer ketika memesan makanan hingga timbul rasa kecewa para customer dan kesibukan para pelayan karena banyaknya customer. Restoran Bukit Randu tidak memiliki sistem pemesanan menu makanan secara online, sehingga kurang dapat bertahan dalam persaingan dengan restoran lainnya. Hal inilah yang mendorong pemilik restoran agar memberikan pelayanan yang terbaik untuk customer dan tidak harus antri ketika memesan makanan.

Bisnis restoran berkesempatan untuk menerapkan teknologi informasi berbasis web di dalam prosesnya. Contoh potensi menerapkan teknologi pemesanan makanan dengan memanfaatkan teknologi smartphone atau komputer yang saat ini menjadi tren teknologi, pelaksanaan pemesanan menu makanan di restoran menjadi teratur dan akurat, selain dapat menghemat waktu dalam antrian pemesanan menu secara digital.

Masalah yang ada pada restoran tersebut adalah belum adanya informasi tentang menu makanan yang lengkap dengan basis web, sering lupa antara apa yang dipesan oleh konsumen dan yang terakhir untuk mendapatkan laporan belum dapat real time saat itu juga karena laporan direkap setelah tutup tempat makannya.

Perancangan dapat didefinisikan sebagai urutan langkah dalam tahapan pengembangan perangkat lunak. Perancangan merupakan aplikasi penerapan beberapa teknik dan prinsip yang bertujuan untuk mendefinisikan hardware agar bisas berfungsi. Rancang bangun merupakan kegiatan pembuatan sistem baru maupun pengembangan sistem yang sudah ada secara keseluruhan”. Kesimpulannya adalah rancang bangun adalah penggambaran, perencanaan, dan pembuatan sketsa atau pengaturan dari beberapa elemen yang terpisah ke dalam suatu kesatuan yang utuh dan berfungsi [4]. Maka dari itu rancang bangun adalah suatu aktifitas yang mengartikan kesimpulan dari analisis ke bentuk software yang kemudian berfungsi untuk menjalankan sistem tersebut. Dikarenakan sebuah sistem akan memiliki tujuan yang berbeda-beda maka sistem tersebut di bangun sesuai dengan masing-masing tujuan tersebut [6].

Ahli yang lain menjelaskan bahwa sistem merupakan suatu jaringan kerja dari prosedur - prosedur yang saling berkaitan. Melakukan kegiatan secara bersama-sama dengan tujuan menyelesaikan suatu tujuan yang ingin dicapai [3]. Sebuah sistem informasi berbasis komputer sudah diteliti dan dirancang yang memiliki manfaat mempermudah perusahaan dalam melakukan pengarsipan surat masuk dan surat keluar pada cv. Sumber Karya Teknik [2]. Sistem Informasi adalah kumpulan dari sub-sub sistem baik fisik maupun non fisik yang saling berhubungan satu sama lain dan bekerja sama secara harmonis untuk mencapai suatu tujuan yang mengolah data menjadi informasi yang berguna [5]. Sedangkan sistem juga dapat didefinisikan sebagai kumpulan dari sub-sub sistem yang saling berhubungan dan memiliki kerjasama yang baik untuk menyelesaikan masalah khusus dengan cara memproses data sehingga mendapatkan nilai yang berbeda karena memiliki penambahan makna dan arti dari sisi pengguna [7].

Penelitian yang berhubungan dengan pemesanan juga sudah diteliti oleh Fuerrero dkk. Dalam papernya dijelaskan bawah kata "to reserve", yaitu menyediakan atau mempersiapkan tepat sebelumnya, sedangkan Reservation yaitu pemesanan suatu tempat fasilitas. Jadi secara umum reservation "Keseluruhan proses kegiatan yang berkaitan dengan pengelolaan inventori atau persediaan tempat pendistribusian produk dan pencatatan keseluruhan transaksi pemesanan" kata reservation dapat disebut juga booking. Makanan tradisional atau kuliner lokal adalah produk makanan yang sering dikonsumsi suatu kelompok masyarakat atau dihidangkan dalam perayaan dan waktu tertentu [1]. Selain itu ada juga penelitian tentang pemesanan makanan yang dilakukan oleh Utama dkk menggunakan platform android memiliki manfaat pengolahan data menjadi fleksibel terutama saat ada penambahan atau perubahan menu makanan atau minuman yang ada [8]. Selain itu penelitian di bidang yang sama juga menyimpulkan bahwa dengan aplikasi berbasis web akan mempermudah dalam melakukan pemesanan makanan dan selain itu dalam aplikasi ini konsumen dapat langsung mengetahui total pembayaran yang ada pada menu tagihan [9]. Penelitian ini menggunakan literature review sebagai berikut:

a. Penelitian yang dilakukan oleh Fandhilah, Danny Pratmanto, A. Fatakhudin pada tahun 2017 dari AMIK BSI Tegal yang berjudul "Rancang Bangun Sistem Informasi Pemesanan Paket Pernikahan Berbasis Web" Penelitian ini membahas tentang aplikasi yang dapat mempermudah atau memperluas lingkup pemasarannya melalui website e-commerce agar dapat menjangkau seluruh Indonesia. Selain sebagai sarana promosi online, aplikasi berbasis website e-commerce dinilai memudahkan konsumen dalam proses pemesanan dan pembelian produk yang mereka inginkan sekaligus.

b. Penelitian yang dilakukan oleh Salman Alfarizi, Arif Rizki Mulyawan, Hasan Basri, pada tahun 2018 dari Universitas Bsi Kampus Karawang yang berjudul "Rancang Bangun Sistem Informasi Penjualan Berbasis Web Dengan Pemanfaatan UML (Unifield Modelling Languange) ", pada penelitian ini penulis membangun sistem informasi penjualan catering nasi box berbasis web, sehingga membantu perluasan jangkauan pemasaran, dengan memanfaatkan media website yang mudah di akses kapanpun, dimanapun. Sistem yang dibangun menggunakan pemanfaataan UML (Unifield Modelling Languange). Kelebihan dari sistem ini, yaitu mempermudah dalam melayani pelanggan secara maksimal. 


\section{METODOLOGI PENELITIAN}

Dalam penelitian ini terdapat 5 langkah yang dilakukan.

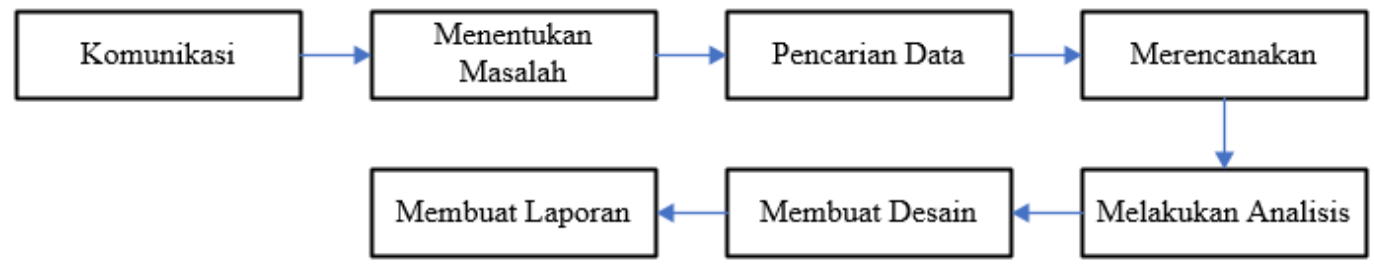

Gambar 1. Metode Penelitian

Dimana langkah pertama dimulai dari komunikasi dengan pihak perusahaan dilanjutkan dengan menentukan permasalahan yang ada, untuk langkah ketiga pencarian data yang dibutuhkan dan diikuti dengan membuat rencana penelitian. Setelah rencana dibuat langkah selanjutnya melakukan analisis dan diikuti dengan membuat desain. Langkah terakhir yaitu membuat laporan akhir yang digunakan sebagai hasil akhir dari penelitian ini.

Penelitian ini menggunakan metode observasi,yaitu mengamati alur proses sistem pemesanan menu makanan yang telah berjalan, mengamati jalannya meeting yang diadakan secara rutin bulan dalam membahas kualitas pelayanan Restoran Bukit Randu Bandara dalam menjalankan sistem operasional prosedur perusahaan, mempelajari dan mengamati laporan hasil penjualan setiap harinya untuk meningkatkan pelayanan terhadap customer Restoran Bukit Randu Bandara. Sedangkan untuk wawancara meliputi proses penilaian kualitas pelayanan yang sedang berjalan, kendala yang dihadapi, kebutuhan sistem penilaian dan pengaruh kualitas pelayanan terhadap unit entry. Untuk studi kepustakaan dilakukan dengan cara mencari segala macam informasi secara riset kepustakaan dan mempelajari buku - buku yang berhubungan dengan masalah yang dihadapi terutama dalam penerapan pemesanan dan pelayanan. Metode perancangan sistemnya menggunakan Unified Modelling Language (UML) dan perancangan sistem menggunakan metode waterfall. Untuk pengujian sistemnya menggunakan Black Box Testing, yaitu proses login, pengelolaan data master dan pelaporan pada masing-masing user.

\section{HASIL DAN PEMBAHASAN}

\subsection{Gambaran Sistem Berjalan Dengan Flowchart Pemesanan Menu Makanan}

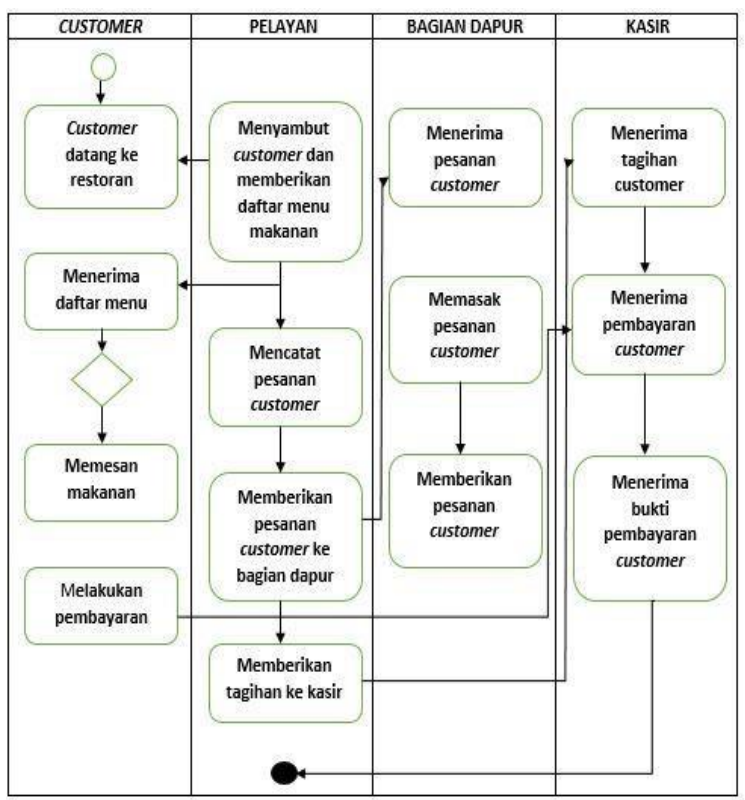

Gambar 2. Flowchart Pemesanan Menu Makanan

Gambar 2 diatas menjelaskan bagaimana proses pemesanan makanan yang dilakukan secara manual sebelum adanya sistem. Customer datang ke restoran selanjutnya pelayan memberikan data menu kepada customer, selanjutnya customer memesan dan dicatat oleh pelayan. Pelayanan datang ke bagian dapur untuk 
memberikan pesanan. Bagian dapur memasak dan memberikan kepada customer dan yang terakhir bagian kasir menerima pembayaran dari customer.

\subsection{Use Case Diagram Usulan}

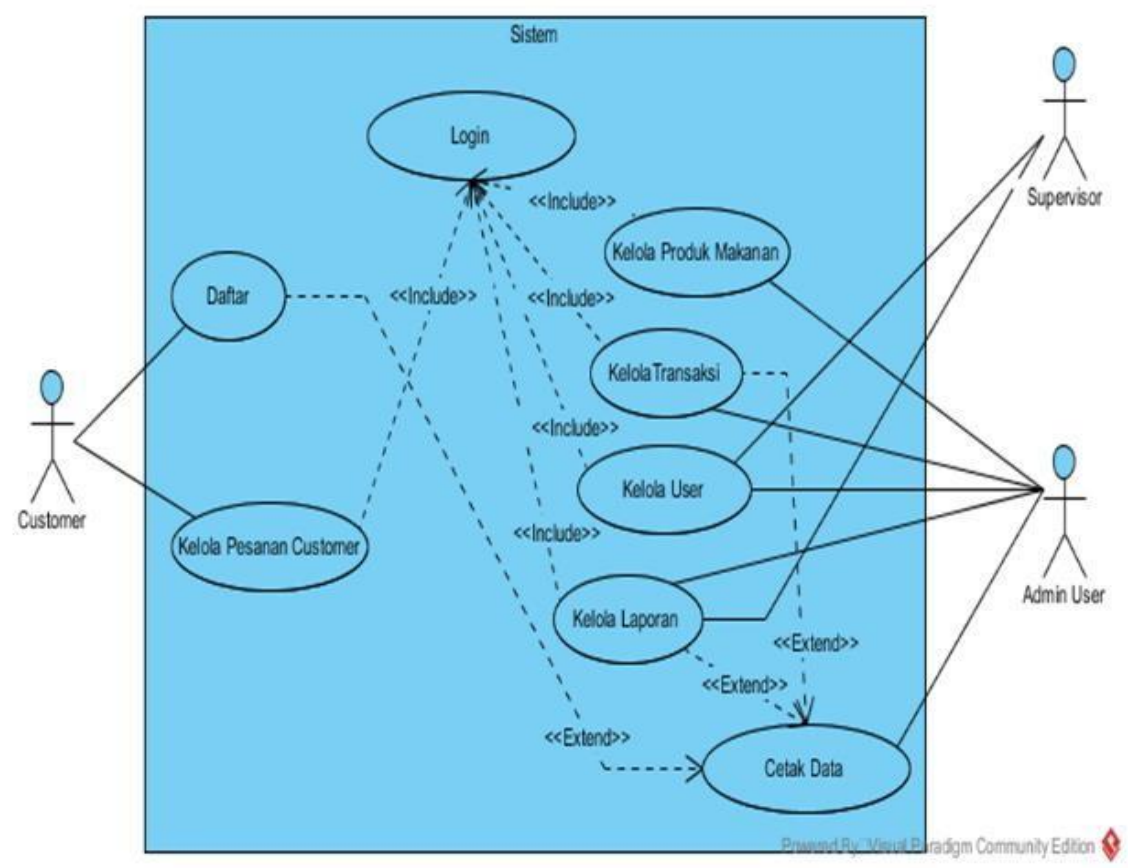

Gambar 3 Use Case Diagram Usulan

Gambar Use Case diatas menjelaskan bagaimana sistem berbasis komputer berinteraksi dengan pengguna. Dalam use case pada gambar 3 diatas terdapat tiga aktor yang terdiri dari customer, supervisor dan admin user. Customer dapat melakukan pemesanan makanan melalui login terlebih dahulu sedangkan supervisor berfungsi untuk melakukan kelola user dan kelola laporan dan admin user dapat melakukan kelola produk, kelola transaksi dan mencetak data. Data yang sudah dicetak admin selanjutnya diberikan kepada customer.

\subsection{Statechart Diagram}

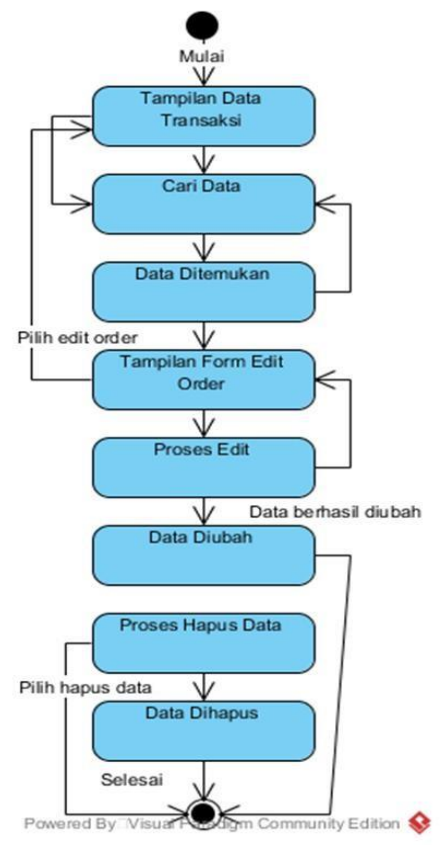

Gambar 4. Statechart Diagram Kelola User 
Gambar statechart diagram kelola user tersebut menjelaskan bagaimana seorang user diinput kedalam sistem dan sebagai apa dalam sistem tersebut. User yang ada dapat diubah, atau dihapus datanya sesuai dengan kebutuhan yang ada.

Tabel 1. Tabel statechart diagram kelola user

\begin{tabular}{ll}
\hline \multicolumn{1}{c}{ Keadaan / statechart } & \multicolumn{1}{c}{ Keterangan } \\
\hline Tampilan data transaksi & Keadaan ini terjadi admin melakukan login sebelumnya \\
Cari Data & Kondisi saat admin telah melakukan cari data \\
Data Ditemukan & Kondisi saat admin telah menemukan data \\
Tampilan Form Edit Order & Kondisi saat admin akan meng-edit user \\
Proses edit & Kondisi saat admin sedang meng-edit user \\
Data diubah & Kondisi saat admin telah berhasil mengubah data user \\
Proses hapus data & Kondisi saat admin melakukan proses hapus data user \\
Data Terhapus & Kondisi saat admin telah menghapus data user \\
\hline
\end{tabular}

\subsection{Activity Diagram}

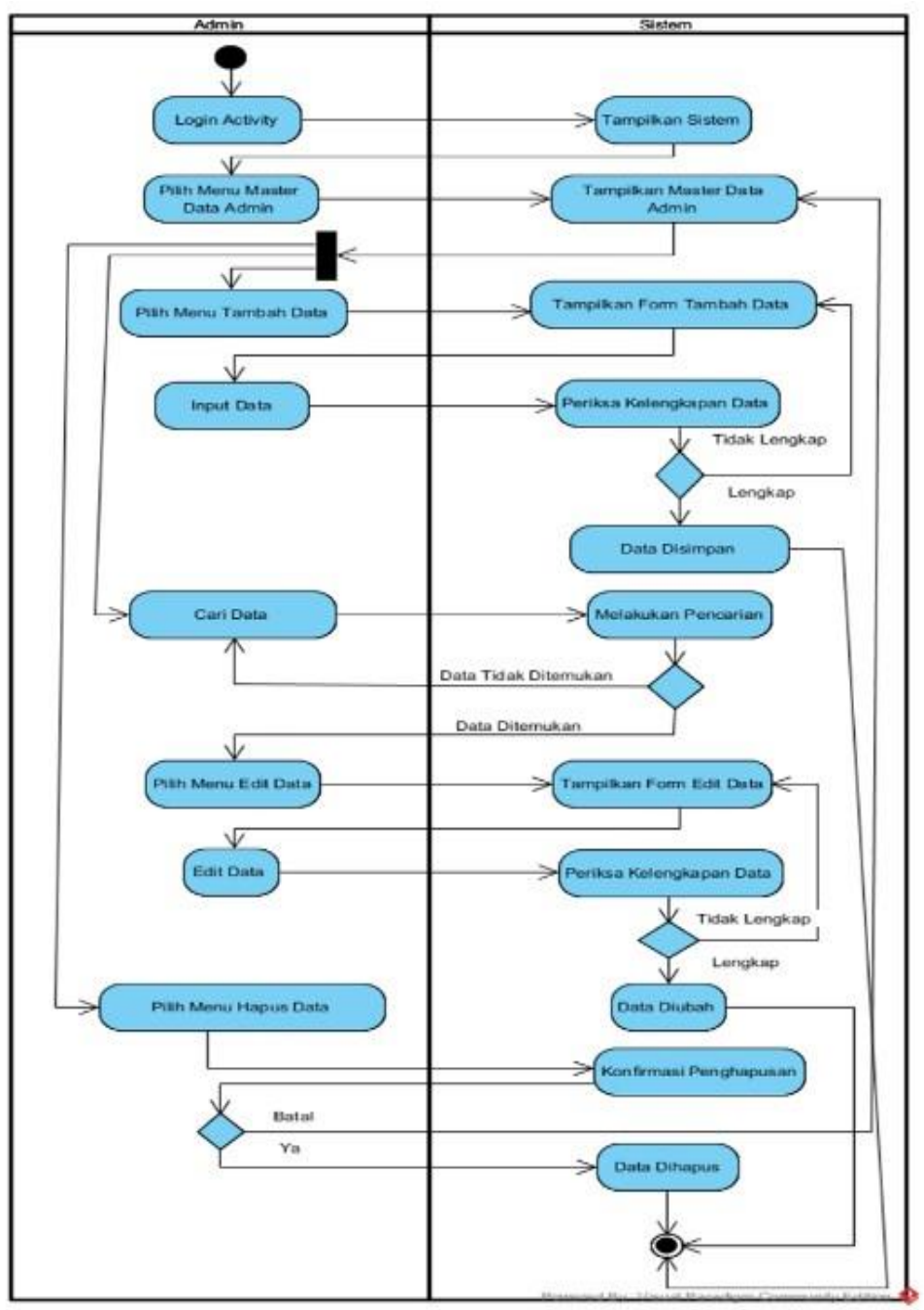

Gambar 5. Activity Kelola User

Di dalam activity diagram kelola user yang pertama kali dlakukan oleh admin yaitu terlebih dahulu melakukan login activity. Kemudian sistem menampilkan pilih menu master data admin. Jika admin ingin mencari data, maka sistem akan melakukan pencarian. Jika data tidak ditemukan, maka admin dapat mencari lagi. Sedangkan jika admin menemukan datanya, maka admin dapat pilih menu edit data dan sistem akan menampilkan form edit data. Lalu admin dapat melakukan edit data, kemudian sistem akan perika kelengkapan data. Jika data lengkap,maka data dapat diubah oleh sistem. Jika tidak, maka sistem akan menampilkan form edit data. 
Saat admin memilih menu master data admin, maka sistem akan menampilkan menunya. Kemudian admin dapat pilih menu tambah data, maka sistem akan menampilkan form tambah data. Setelah itu admin dapat melakukan input data, maka sistem akan memeriksa kelengkapan data. Jika data tidak lengkap, maka sistem akan menampilkan form tambah data. Jika lengkap, maka data akan disimpan oleh sistem.

Begitu pula jika admin pilih menu hapus data, maka sistem akan melakukan konfirmasi penghapusan data. Jika iya, maka sistem akan menghapus data. Jika batal, maka sistem akan menampilkan master data admin.

\subsection{Sequence Diagram}

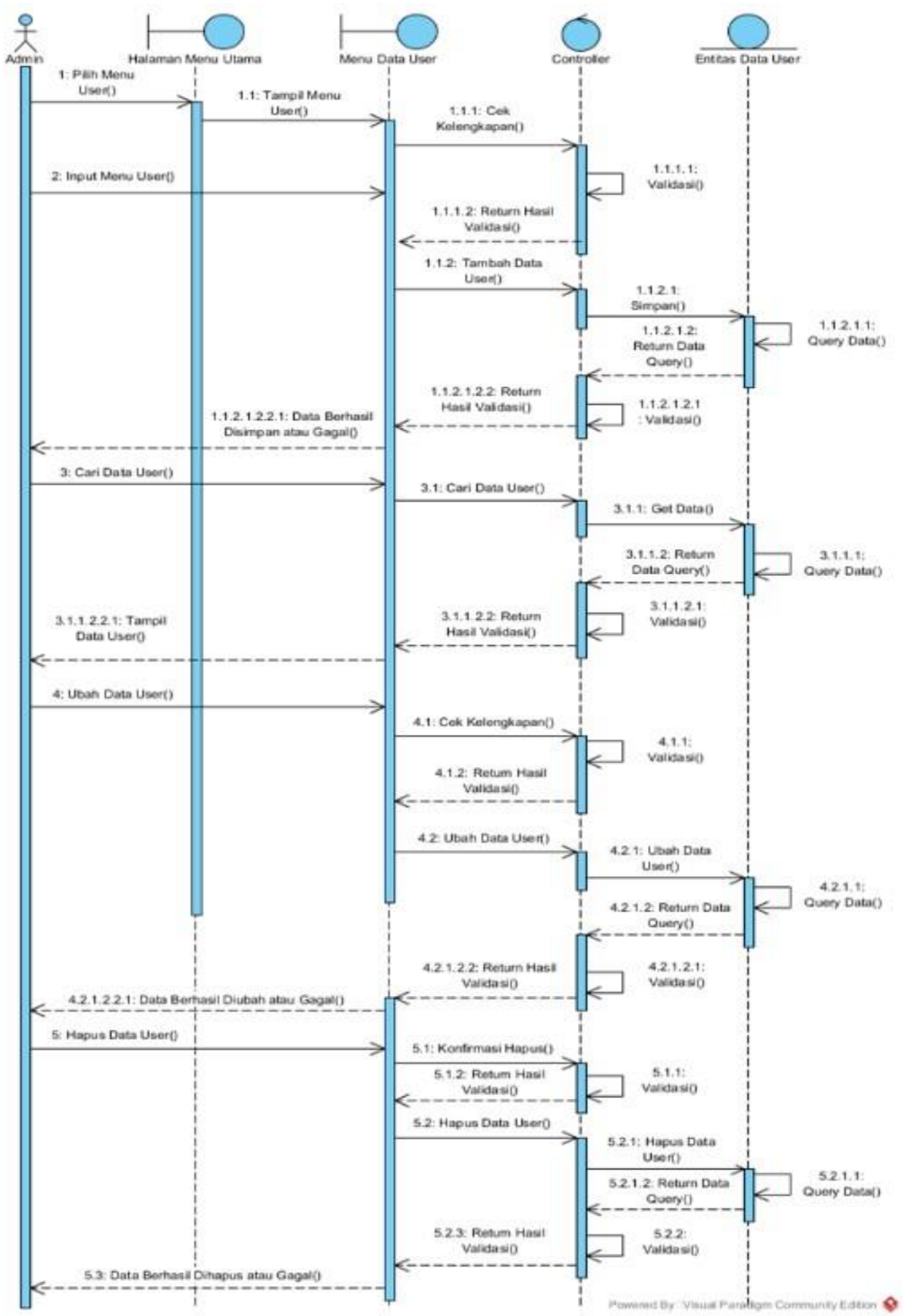

Gambar 6. Sequence Diagram Kelola User

Sequence diagram untuk kelola user dijelaskan dalam gambar 6 diatas, dimana seorang user berhubungan dengan sistem secara teknis. User dapat memilih menu utama sehingga tampil menu utamanya setelah itu cek kelengkapan apakah sesuai atau tidak dengan data yang ada didalam database. 
Dari gambar 6 dapat dilihat bahwa seorang admin dapat memilih menu user, kemudian input menu user. Lalu cek kelengkapan datanya. Jika data sudah lengkap, maka pilih menu tambah data user dan menyimpannya. Seorang admin juga dapat cari data user dan dapat mengecek validasi datanya. Begitu juga seorang admin dapat mengubah data user dan menghapus data user. Untuk menghapus user, maka seorang admin akan mendapat konfirmasi hapus data.

\subsection{Design User interface}

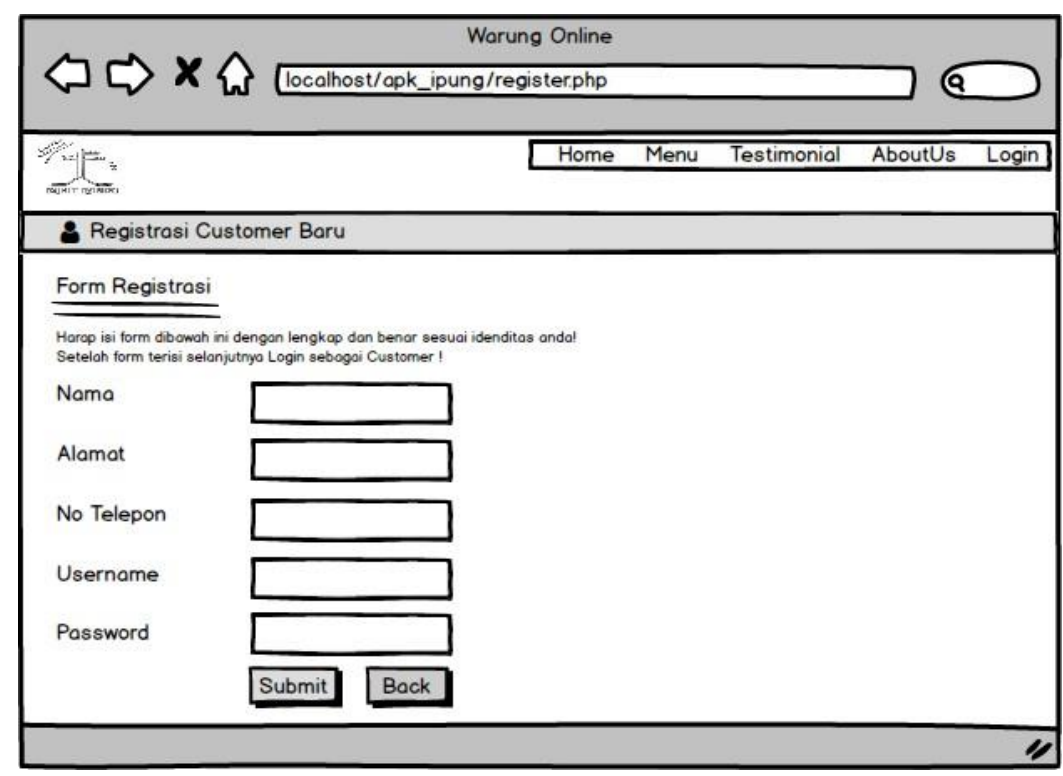

Gambar 7. Implementasi Registrasi

Gambar 7 datas menunjukkan implementasi registrasi dari pembeli dimana pembeli diharapkan melakukan input data pribadi. Data tersebut akan di simpan didalam database sehingga jika ada promo maka pelanggan tersebut akan mudah untuk didata seberapa banyak datang ke rumah makan ini.

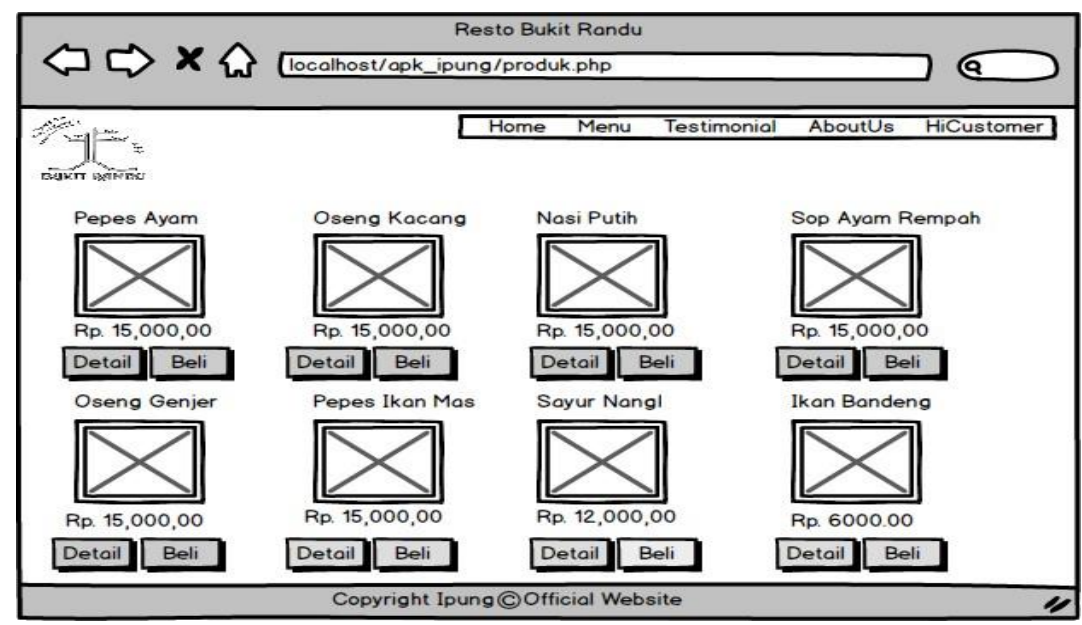

Gambar 8. Implementasi Produk

Tampilan produk yang disajikan di tampilkan dalam form implementasi produk, dalam form tersebut terdapat menu manakanan yang dijual dan bisa juga di lihat detail bahan yang digunakan serta menampilkan harganya. Jika customer ingin membeli makanan atau minuman yang ada maka tinggal klik menu Beli. Setelah klik tombol beli, maka secara otomatis akan ditampilkan berapa total harga yang akan di bayarkan, sehingga bisa digunakan sebagai kontrol juga bagi customer. 


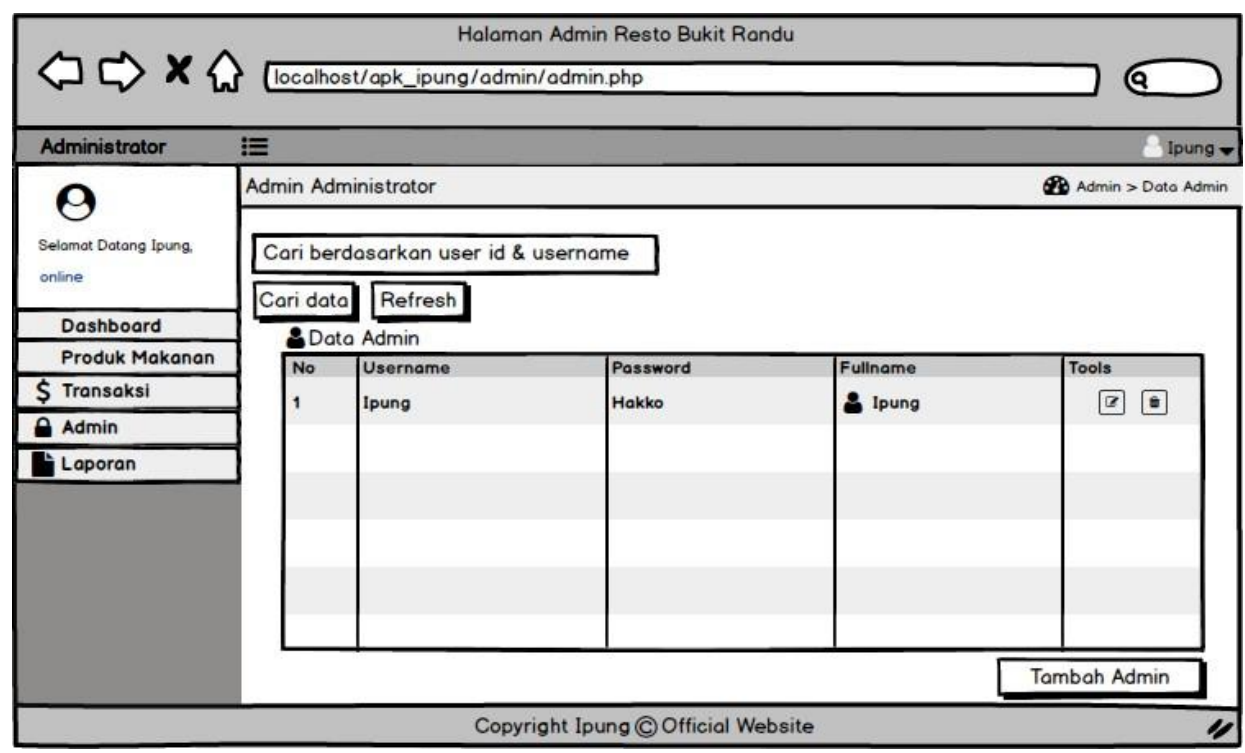

Gambar 9. Implementasi Admin

Gambar implementasi admin berisi tentang produk makanan yang disajikan dan sekaligus harganya, proses transaksi yang dilakukan, admin dan laporan tentang produk makanan dan minuman, siapa adminnya, dan jumlah uang yang diterima dapat dilihat secara real time.

\section{KESIMPULAN}

Website dapat membantu memberikan informasi ke customer sehingga customer luas dapat mendapat informasi yang update. Dengan adanya sistem ini dapat menjadi salah satu solusi bagi customer yang ingin membeli makanan tanpa harus mengantri. Mempermudah pengusaha restoran untuk mendapatkan customer dan memanjakan customer dengan adanya sistem informasi ini. Komputerisasi sistem bukanlah suatu jaminan bagi keberhasilan suatu tujuan, hal ini dikarenakan komputer hanyalah suatu sarana pendukung. Dalam hal ini peranan manusia sangat diutamakan sebagai penanggung jawab sistem tersebut.

\section{DAFTAR PUSTAKA}

[1] Guerrero, L et al. 2010. "Perception of traditional food products in six European regions using free word association”. Food Quality and Preferences, 21: 235-233

[2] Pertiwi, D.D and Taufiq, R. 2020. "Analisis dan Desain Sistem Informasi Pengolahan Nilai Siswa di SMK Avicena Rajeg”, J. Tek. Inform. Univ. Muhammadiyah Tangerang. ISSN: 2549-0710

[3] Jogiyanto HM. (2005). Analisis dan Desain. Yogyakarta: Andi

[4] Roger S. Pressman. (2012). Rekayasa Perangkat Lunak Pendekatan Praktisi (Buku Satu). Yogyakarta: Penerbit Andi.

[5] Susanto, Azhar. (2013). Sistem Informasi Akuntansi. Bandung: Lingga jaya

[6] Sutabri, Tata. (2012). Analisis Sistem Informasi. Yogyakarta: Andi.

[7] Taufiq, Rohmat. (2018). Pengantar Sistem Informasi. Jakarta. Mitra Wacana Media.

[8] Utama, Deni, Johar, Asahar, Coastera, FF. (2016). Aplikasi Pemesanan Makanan dan Minuman Restaurant Berbasis Client Server dengan Platform Android dan PHP Menggunakan Metode Centralzied DBMS Architecture. Jurnal Rekursif, Vol. 4 No. 3 September 2016. ISSN 2303-0755

[9] Defrina, Debbie dan Lestari, DP. (2017). Aplikasi Pemesanan Makanan dan Minuman Online Berbasis Mobile Browser pada Restoran Tiga Saudara. Jurnal Ilmiah Informatika dan Komputer Vo. 22 No. 3. Desember 2017 